\title{
Radiological findings of unilateral tuberculous lung destruction
}

\author{
Diego Varona Porres ${ }^{1} \cdot$ Oscar Persiva $^{1} \cdot$ Esther Pallisa $^{1} \cdot$ Jordi Andreu $^{1}$
}

Received: 22 August 2016 / Revised: 26 January 2017 / Accepted: 1 February 2017 / Published online: 14 February 2017

(C) The Author(s) 2017. This article is published with open access at Springerlink.com

\begin{abstract}
Objectives The aim of this report is to identify the radiological findings of unilateral tuberculous lung destruction (UTLD).

Materials and methods Thirteen patients with (UTLD) were reviewed from 1999 to 2014. Only patients with radiological evidence of absence of pulmonary parenchyma preserved were included. Clinical and demographic data were obtained and radiological studies (chest radiograph and CT) were retrospectively reviewed.

Results The left lung was more commonly involved (85\%). The following radiological findings were found in all cases: a decrease in the diameter of the pulmonary vessels of the affected lung, herniation of the contralateral lung and hypertrophy of the ribs and/or thickening of extrapleural fat. Two radiological patterns were identified: UTLD with cystic bronchiectasis $(85 \%)$ and UTLD without residual cystic bronchiectasis (15\%). Forty-six per cent of cases had respiratory infection symptoms with presence of air-fluid levels in the affected lung as the most common finding in these patients.

Conclusions Total unilateral post-tuberculous lung destruction is an irreversible complication with the following main radiological features: predominantly left-sided location, decreases in the diameter of the ipsilateral pulmonary vessels, herniation of the contralateral lung and hypertrophy of the ribs and/or thickening of extrapleural fat.
\end{abstract}

Diego Varona Porres

dvaronaporres@gmail.com

1 Hospital Vall d'Hebrón. Radiology department, Passeig Vall d' Hebrón 119, 08035 Barcelona, Spain
Teaching Points

- Unilateral tuberculous lung destruction is an irreversible complication of tuberculosis.

- Left-side predominance and herniation of the contralateral lung are characteristic.

- Decreased diameter of the ipsilateral pulmonary vessels occurred in all patients.

- The pattern with residual cystic bronchiectasis is the most frequent.

- Superimposed non-tuberculous infections may affect the destroyed lung.

Keywords Tuberculosis, pulmonary $\cdot$ Infections, respiratory . CT scanner, X-ray $\cdot$ Radiography $\cdot$ Thoracic

\section{Introduction}

Tuberculosis (TB) remains one of the world's deadliest communicable diseases. In 2014, an estimated 9.6 million people developed TB and 1.5 million died from the disease [1]. The appearance of strains resistant to pharmacological treatment and immigrant influx from countries with a high incidence of this disease may increase the possibility of TB-related complications and sequelae in developed areas.

Pulmonary TB can be a source of severe complications, such as unilateral lung destruction occurring in the final phase of progressive disease or disease reactivation. This complication has been previously reported in a recent review of 5,926 cases of TB in 74 patients (1.3\%) [2]. Lung destruction, particularly in association with bronchiectasis, is easily colonised by bacteria and fungi [3] and this may be one reason why pulmonary TB is associated with considerable morbidity and mortality [4]. The related literature contains few references to this complication [5-7], also known as the left bronchus 
syndrome. Pulmonary destruction by TB, particularly total destruction of an entire lung, is currently uncommon, and the imaging features may be confused with those of other entities. Hence, it is important to be familiar with the most significant radiological findings in this condition.

In this report, we present a review of 13 patients with UTLD secondary to TB attended in our centre, with the aim of describing the radiological findings in radiograph and chest $\mathrm{CT}$ of this late and uncommon complication of TB.

TUTLD is a late complication that requires years to develop; so it is difficult to estimate the influence of other superimposed nontuberculosus infections and to assemble a large sample or perform a prospective study with significant data. However, for this review article we were able to collect these cases to discuss the typical findings of UTLD against the background of findings in patients of our own department. This instructive patient sample was not obtained from a database containing all tuberculosis cases occurring in the study period; therefore the incidence of this complication in our setting will not be discussed in detail.

\section{Epidemiology}

Among the 13 patients comprising the series, there was a male predominance ( 9 males and 4 females) and the age range was 27 to 83 years (mean 55 years). All the patients were diagnosed with chest tuberculosis during childhood or youth. Two patients were from countries with a higher incidence of TB than Spain [8] (Table 1).

Regarding symptomatology in these patients, most of them presented with dyspnoea or a respiratory infection event. One patient showed self-limited haemoptysis probably related to the existence of bronchiectasis.

With regard to the anti-TB treatment received, it was not collected in the clinical records of five patients and available for the nine patients remaining. Three patients were treated with collapse therapy, which could have promoted the lung destruction. Tuberculous reactivation was treated with medical treatment in one patient. The remaining five patients $(5 / 13$, $38.5 \%$ ) were treated with anti-TB drugs with tuberculous reactivation in one case treated again with drugs.

Four patients were diagnosed with chronic obstructive pulmonary disease (COPD) $(4 / 13,31 \%)$. The relationship between TB and COPD is well recognised and can increase with age [9]. The mean age of COPD patients in our study was quite high (73.5 years, range 66-81), in keeping with these reported data. A proportional relationship between lung function impairment and the degree of abnormalities in chest X-rays has been reported in a previous study [10]; however, we were unaware of the pulmonary function status of our patients.

\section{Radiological findings}

\section{Chest radiograph findings}

PA chest X-ray showed diffuse opacity of a whole hemithorax with severe ipsilateral mediastinal deviation, mimicking an almost complete lung collapse, in one case. The remaining 12 patients presented with a small hemithorax with aireated lung secondary to contralateral lung herniation and/or cystic bronchiectasis or cavitated lesions. Lateral projection showed retrosternal hyperclarity in all patients in relation to the existence of lung herniation contralateral to the UTLD.

\section{CT findings}

On retrospective review of the $\mathrm{CT}$, the patients were classifiable in two main patterns: unilateral lung destruction with residual cystic bronchiectasis (11/13, 85\%) (Fig. 1) and unilateral lung destruction without residual cystic bronchiectasis $(2 / 13,15 \%)$ (Fig. 2). There was a clear left-sided predominance $(11 / 13,85 \%)$. All patients with UTLD presented three common findings: a decrease in the diameter of the pulmonary artery and pulmonary veins of the affected lung (Fig. 3), anterior and posterior (retrocardiac) herniation of the contralateral lung (Fig. 1c) and hypertrophy of the ribs and/or an increased extrapleural fat. The contralateral lung herniation consisted of anterior herniation of the upper lobe or middle lobe $(12 / 13,92 \%)$ or posterior herniation of the lower lobe $(11 / 13,85 \%)$, with both lobes being affected simultaneously in most cases $(10 / 13,77 \%)$.

\section{Lung destruction and bronchial tree anomalies}

Pulmonary tuberculosis infection leads to lung destruction through a process of cavitation, spread of disease to other areas and secondary development of fibrosis [2].

Lung destruction due to primary progressive TB is generally unilateral, with upper lobe predominance [2]. The presence of peribronchial or hilar lymph adenopathies, a common finding in primary infection that is occasionally accompanied by endobronchial injury, can give rise to bronchial obstruction. The lymph adenopathies may disappear, while the bronchial stenosis persists. Bronchial obstruction due to caseum, pus or an excess of mucus can lead to a secondary pyogenous infection or lobar collapse, with resulting atelectasis due to fibrosis of a lobe (partial) or the entire lung.

Lung destruction due to TB reactivation presents differences relative to the primary disease. It consists of pulmonary dissemination and secondary fibrosis, and the hemithorax contralateral to the infection is often affected $[2,11]$. 
Table 1 Demographic and clinical data of the study patients

\begin{tabular}{|c|c|c|c|c|c|}
\hline & Sex/age & $\begin{array}{l}\text { Country of } \\
\text { origin }\end{array}$ & Medical history & TB treatment & Symptoms \\
\hline 1 & Female/43 years & Guinea & TB at 24 years & Complete treatment with 4 drugs for 24 months & Fever \\
\hline 2 & Male/27 years & Ecuador & $\begin{array}{l}\text { TB at } 20 \text { years } \\
\text { Mother died of TB } \\
\text { at } 20 \text { years }\end{array}$ & Not recorded in medical history & $\begin{array}{l}\text { Cough with mucus } \\
\text { expectoration and left } \\
\text { pleuritic pain }\end{array}$ \\
\hline 3 & Male/83 years & Spain & TB in infancy & Not recorded in medical history & $\begin{array}{l}\text { Weakness and paresthesia } \\
\text { of the hands }\end{array}$ \\
\hline 4 & Female/38 years & Spain & TB at 28 years & Complete pharmacological treatment for 6 months & $\begin{array}{l}\text { Sudden dyspnoea due to } \\
\text { right tension } \\
\text { pneumothorax }\end{array}$ \\
\hline 5 & Female/69 years & Spain & $\begin{array}{l}\mathrm{TB} \text { at } 12 \text { years, } \\
\text { reactivation at } \\
55 \text { years } \\
\text { Kidney TB }\end{array}$ & $\begin{array}{l}\text { Collapse therapy and intramuscular streptomycin during } \\
\text { adolescence. Reactivation } 14 \text { years ago treated for } 6 \text { months } \\
\text { with drugs not specified in medical history }\end{array}$ & Haemoptysis \\
\hline 6 & Female/68 years & Spain & $\mathrm{TB}$ at 29 years & $\begin{array}{l}\text { Complete pharmacological treatment during patient's second } \\
\text { pregnancy }\end{array}$ & No symptoms \\
\hline 7 & Male/73 years & Spain & $\begin{array}{l}\text { TB in youth } \\
\text { COPD }\end{array}$ & Collapse therapy & $\begin{array}{l}\text { Fever and purulent } \\
\text { expectoration }\end{array}$ \\
\hline 8 & Male/72 years & Spain & $\begin{array}{l}\text { TB at } 18 \text { years, } \\
\text { reactivation at } \\
55 \text { years } \\
\text { Long-term COPD }\end{array}$ & $\begin{array}{l}\text { Pharmacological treatment for } 12 \text { months at } 18 \text { years. } \\
\text { Reactivation treated with } 3 \text { drugs for } 18 \text { months }\end{array}$ & $\begin{array}{l}\text { Dyspnoea, cough and } \\
\text { purulent expectoration }\end{array}$ \\
\hline 9 & Male/81 years & Spain & $\begin{array}{l}\text { TB at } 25 \text { years } \\
\text { Long-term COPD }\end{array}$ & Not recorded in medical history & $\begin{array}{l}\text { Dyspnoea, cough, } \\
\text { purulent expectoration, } \\
\text { chest pain and fever }\end{array}$ \\
\hline 10 & Male/73 years & Spain & $\begin{array}{l}\text { TB at } 16 \text { years } \\
\text { Chronic empyema }\end{array}$ & Therapeutic pneumothorax & $\begin{array}{l}\text { Evaluation for } \\
\text { noninvasive } \\
\text { mechanical ventilation }\end{array}$ \\
\hline 11 & Male/58 years & Spain & $\begin{array}{l}\text { TB at } 30 \text { years } \\
\text { HIV }\end{array}$ & $\begin{array}{l}\text { Complete pharmacological treatment with } 3 \text { drugs for } \\
9 \text { months }\end{array}$ & Dyspnoea \\
\hline 12 & Male/66 years & Spain & $\begin{array}{l}\text { TB in infancy } \\
\text { COPD }\end{array}$ & Not recorded in medical history & $\begin{array}{l}\text { Dyspnoea and } \\
\text { expectoration }\end{array}$ \\
\hline 13 & Female/76 years & Spain & $\begin{array}{l}\text { TB at } 28 \text { years } \\
\text { Sleep apnoea } \\
\text { syndrome }\end{array}$ & Not recorded in medical history & Non-productive cough \\
\hline
\end{tabular}

TB, tuberculosis; COPD, chronic obstructive pulmonary disease; HIV, human immunodeficiency virus
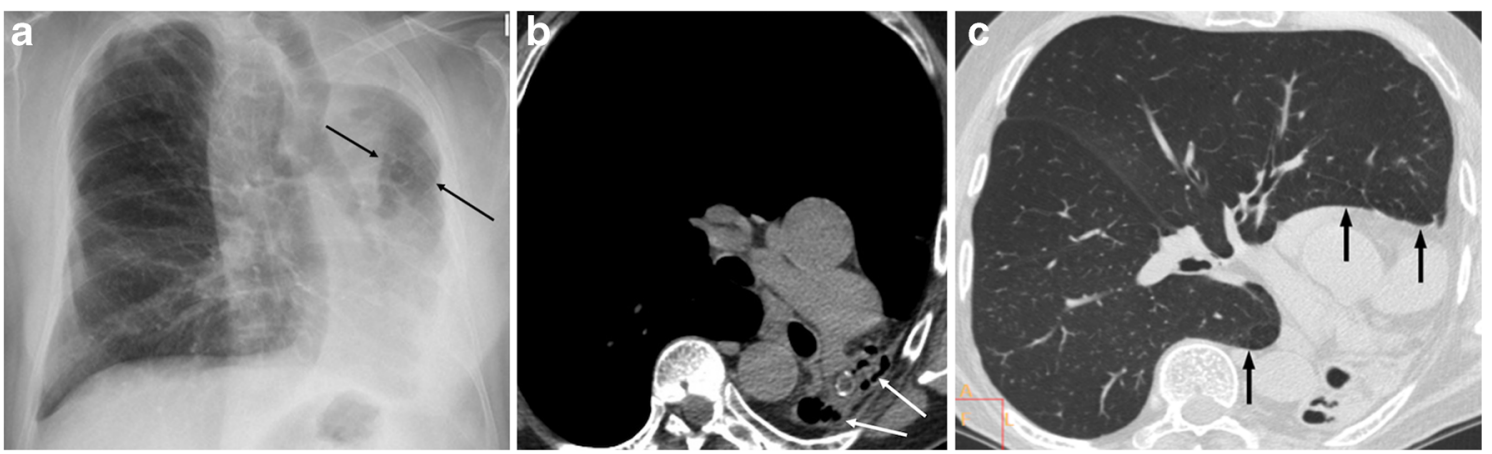

Fig. 1 A 58-year-old male with a history of pulmonary TB 20 years previously presented with dyspnoea on exertion. (a) The chest radiograph shows marked loss of left lung volume, with an isolated hyperlucent lesion (arrows) that reflects herniation of the contralateral lung toward the left hemithorax. (b) Unenhanced multislice CT depicts total destruction of the left lung with residual cystic bronchiectasis (arrows) and herniation of the right lung toward the left hemithorax. (c) Unenhanced multislice CT clearly demonstrates herniation of the right lung toward the left hemithorax, that is, anterior herniation of the upper lobe and posterior herniation of the lower lobe (arrows) 


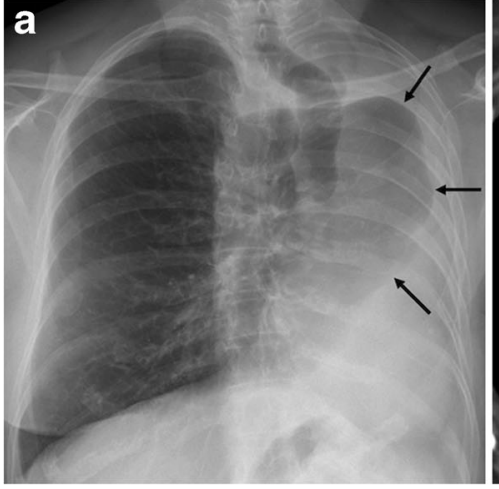

Fig. 2 A 68-year-old female with a background of pulmonary TB at age 29 was seen at our hospital for a breast cancer follow-up study. (a) Chest radiography shows marked loss of left lung volume and herniation of the contralateral lung (arrows). (b) Contrast-enhanced multislice CT

Although the posterior and apical segments of the upper lobes are the most common sites of pulmonary TB, with a similar incidence on both sides, lung destruction due to primary or postprimary disease most commonly occurs on the left side, in the same way as the fibrotic phase of endobronchial TB [3, 12]. This finding was observed in 11 patients in our review $(85 \%)$, in agreement with other retrospective studies in which left-side predominance ranged from $63 \%$ to $80 \%[4-7,13]$. The explanation resides in the anatomy of the left pulmonary bronchus, which crosses a narrow anatomical space, the aorto-pulmonary window, and is longer and smaller in diameter than the main right bronchus [14]. These factors all favour bronchial collapse due to adjacent lymph adenopathy. In addition, the more horizontal course of the main left bronchus can have an effect on drainage of secretions, favouring obstruction. The CT results in our series support this theory, with left bronchial stenosis as the most common finding.

\section{Decreased diameter of pulmonary arteries and veins}

One radiological finding of note was the clear decrease in the diameter of the ipsilateral pulmonary artery observed in all

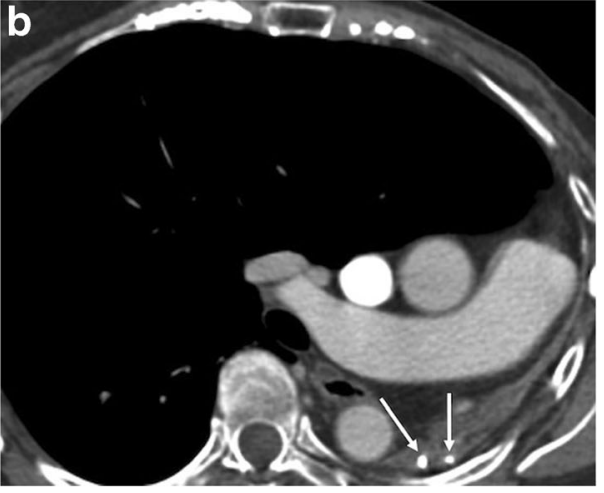

demonstrates total left lung destruction with no residual cystic bronchiectasis. Calcifications are seen in the remnant lung (arrows), and the contralateral lung is herniated

cases of total lung destruction. This finding is consistent with a reported haemodynamic factor that contributes to bacterial dissemination to the rest of the lung [14]. It consists of shunts between the pulmonary and bronchial arteries, occurring in response to the reduction in pulmonary artery flow associated with bronchial obstruction, an accumulation of secretions, or parenchymal infection. The shunts produce retrograde broncho-pulmonary flow that enhances bacterial dissemination and lung destruction when it is associated with lymphatic stasis and increased oxygen tension in the affected lung [14].

Ipsilateral pulmonary veins also showed a decreased calibre in every case; therefore UTLD should be included in the differential diagnosis of decreased size of pulmonary veins [15].

\section{Hypertrophy of ribs and thickening of extrapleural fat}

Hypertrophy of the ribs and/or increased extrapleural fat was present in all patients and is likely a reflection of the lengthy evolution and chronic disease (Fig. 4). Patients with chronic inflammatory conditions of the lung or pleura, especially tuberculosis, may have hypertrophy of the ribs on the affected

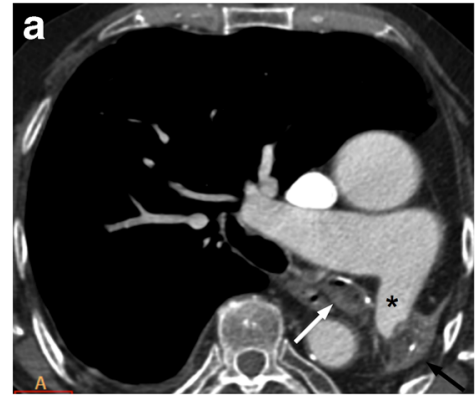

Fig. 3 An 83-year-old male who had pulmonary TB in infancy came to our hospital for weakness and paresthesia of both hands. (a) On contrastenhanced multislice CT, total left lung destruction with calcifications (black arrow) in the remnant lung, occupation of the left main bronchus

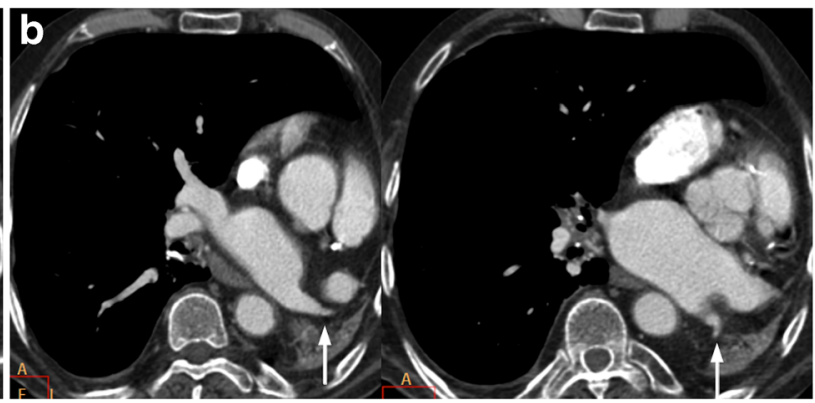

(white arrow) and decreased diameter of the left main pulmonary artery (asterisk) are visualised. (b) The diameter of the ipsilateral superior and inferior pulmonary veins is also decreased (arrows) 


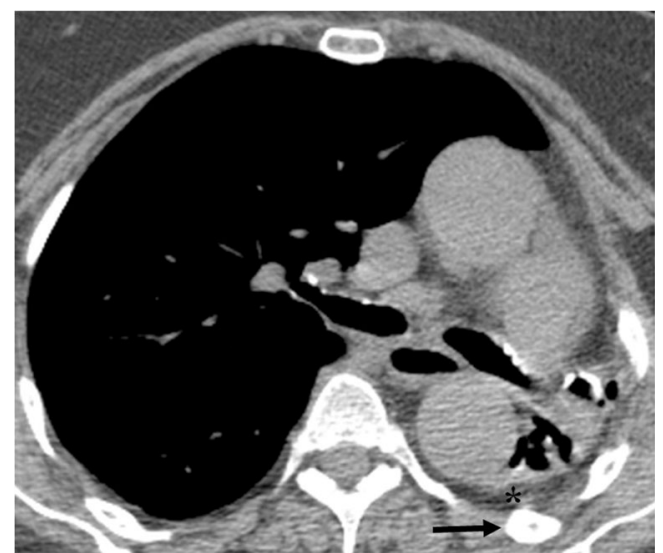

Fig. 4 A 76-year-old female with TB history in infancy presenting with dry cough for 1 month. Non-enhanced CT shows total unilateral left lung destruction with bronchiectasis. Upper ipsilateral ribs are hypertrophic (black arrow) and extrapleural fat proliferation is also evident (asterisk)

side. This finding is probably due to chronic reactive periostitis associated with localised hyperaemia [16].

Extrapleural fat thickening is a previously described finding in patients with empyema of the affected side and may increase to up to two to three times more than the contralateral side [17]. In case of thoracic tuberculosis, it has been described in chronic empyema and fibrothorax and is considered a finding suggesting chronicity [11].

\section{Superinfections}

Six patients $(6 / 13,46.1 \%)$ had symptoms consistent with respiratory infection (fever and expectoration), and four showed the following radiographic findings: pulmonary air-fluid levels $(2 / 6,33.3 \%)$, pulmonary air-fluid levels and mucus impaction $(1 / 6,16.6 \%)$ (Fig. 5) and centrilobular pulmonary nodules $(1 / 6,16.6 \%)$. In four patients, microorganisms were isolated from sputum samples or bronchoalveolar lavage: Pseudomona aeruginosa (3/4, 75\%), Streptococcus pneumoniae $(1 / 4,25 \%)$ and Haemophilus influenzae (1/4, $25 \%$ ).

Tuberculosis infection tends to be inactive in cases of lung destruction, making the diagnosis more difficult. The microbiological study of secretions often shows other microorganisms [2], which may be of bacterial origin, such as those described in our review and indicating processes of superinfection. The isolated microorganisms in our series (Pseudomonas aeruginosa, Streptococcus pneumoniae, and Haemophilus influenza) are consistent with the findings from a prospective study in hospitalised patients with acute COPD exacerbations [18] and similar to previous literature [19]. All COPD patients in our study had symptoms suggestive of respiratory infection and also had positive cultures or positive radiology; hence, the presence of respiratory superinfection in our patient sample with UTLD might be falsely increased because of the association with COPD. The incidence of respiratory infections may be falsely increased because of the presence of COPD, as it has been reported that respiratory infections cause the majority of COPD exacerbations [20].

In patients treated in our hospital, we observed two radiological patterns: unilateral destruction with cystic bronchiectasis and unilateral destruction without cystic bronchiectasis. All patients with superinfections signs had the total destruction with cystic bronchiectasis pattern. Therefore, the pattern of lung destruction with cystic bronchiectasis is associated with the highest risk of superinfection.

\section{Other findings}

The contralateral lung in post-tuberculous lung destruction showed residual lesions, such as bronchiectasis (Fig. 6), bronchial thickening, calcified granulomas and atelectasis in ten patients $(10 / 13,78 \%)$. Pulmonary, mediastinal, pleural,

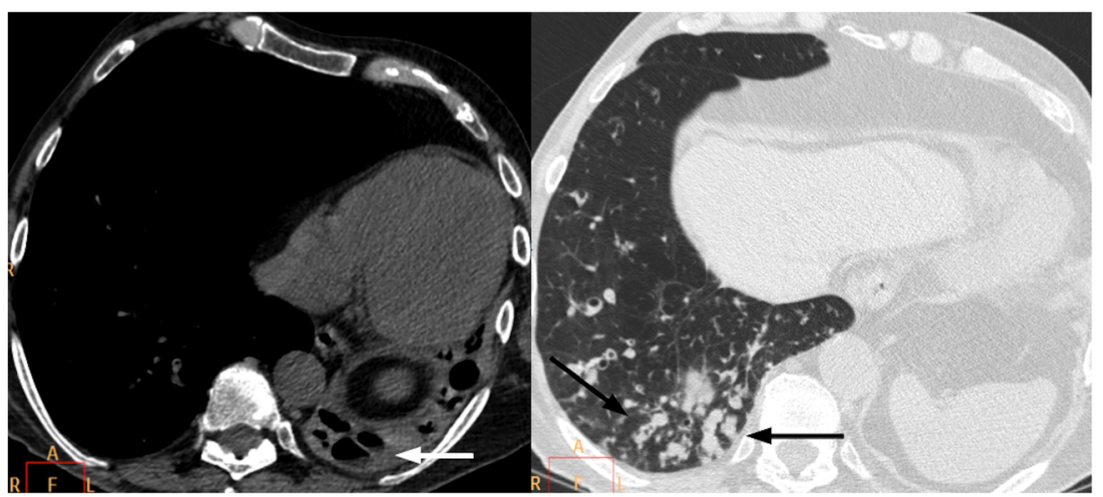

Fig. 5 A 73-year-old male with a history of pulmonary TB as a youth and chronic obstructive pulmonary disease was seen for fever and purulent expectoration. Unenhanced multislice CT depicted complete left pulmonary destruction with residual cystic bronchiectasis associated with air-fluid levels (white arrow in the right image) and airway occupation with mucus impaction in the lower right lobe (black arrows in the left image). Sputum culture was positive for Pseudomona aeruginosa and Streptococcus pneumoniae. Antibiotic treatment was established without success, and the patient died 15 days after hospitalisation 


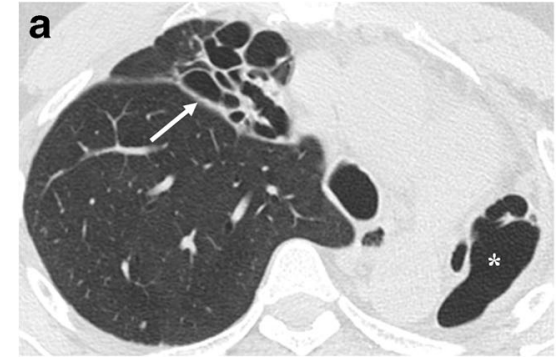

Fig. 6 A 43-year-old female with TB history in her youth and recurrent infections presenting with fever. Sputum culture was postive for Pseudomona aeruginosa. (a) Non-enhanced CT shows total unilateral left lung destruction with bronchiectasias (asterisk) and lung atelectasis

pericardial and abdominal calcifications were seen in ten patients $(10 / 13,78 \%)$ and were visible on plain films in four of them (Fig. 7).

\section{Differential diagnosis}

The diagnosis of this entity is straightforward if the previous history of TB is clear and well documented on clinical records. When radiological findings consistent with lung destruction are seen, we should consider any granulomatous disease. Similar features can be observed in some types of mycosis, although the fibrosis and mediastinal displacement are never as severe as in TB [2]. The differential diagnosis should also include total lung collapse, chronic pleural disease, previous lung surgery and pulmonary agenesis/hypoplasia. Pulmonary agenesis/hypoplasia can affect both lungs and may be indistinguishable from UTLD. In most cases, however, the diameter of the pulmonary artery is normal [21] and this contrasts with the smaller diameter of the pulmonary artery seen in all patients with UTLD. UTLD should be included in the differential diagnosis of causes of decreased calibre pulmonary arteries and veins. Residual lesions in the contralateral lung and calcifications were present in a high percentage of patients in our series and can also help to support the diagnosis of posttuberculous lung destruction along with the clinical history of previous lung tuberculosis.

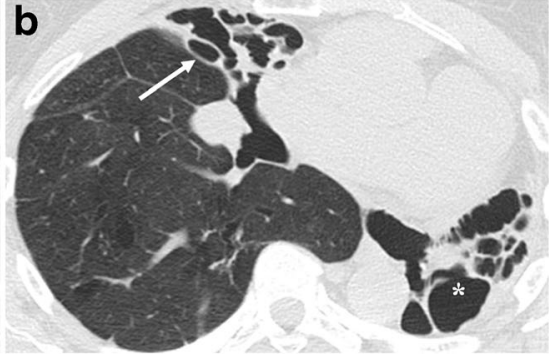

with saccular bronchiectasis in the right upper lobe (white arrow). (b) Right middle lobe atelectasis is also seen along with bronchiectasis (white arrow)

\section{Management}

Several papers in the medical literature describe surgical treatment of the UTLD by means of pneumonectomy in certain cases, though this treatment is considered high risk [13, 22-24]. Cases of postpneumonectomy-like syndrome have also been described in patients with UTLD; accordingly this condition should be included in the differential diagnosis of dyspnoea in this group of patients [25, 26].

In our daily practice all patients were incidentally diagnosed as a consequence of signs and symptoms of respiratory infection or dyspnoea. Due to the appearance of infections in these patients an imaging examination may be necessary for the diagnosis.

\section{Conclusion}

In conclusion, UTLD is an irreversible complication of pulmonary TB that presents with characteristic radiological findings: unilateral volume loss predominantly in the left lung, decreased diameter of the ipsilateral main pulmonary artery and pulmonary veins, and herniation of the contralateral pulmonary parenchyma. The pattern with residual cystic bronchiectasis is the most frequent. Usually the tuberculous infection is inactive, although associated non-tuberculosis infection may develop and affect the destroyed lung. Therefore, a correct diagnosis and radiological follow-up are very important in these patients.
Fig. 7 Same patient as in Fig. 4. (a) Chest radiograph shows total unilateral left lung destruction and calcification projected on the upper half of left hemithorax. (b) Non-enhanced CT confirms the presence of left upper pleural calcification in correspondence with the calcification seen on chest radiograph
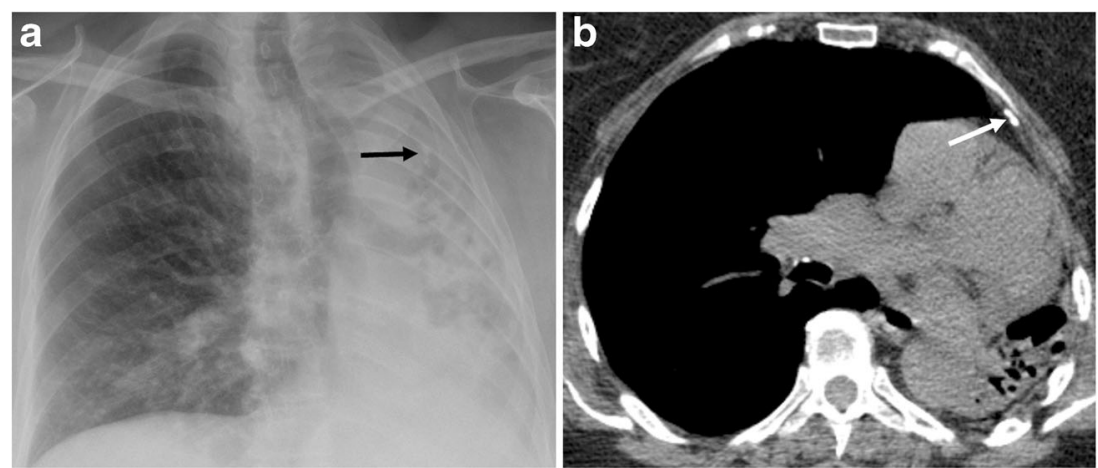
Open Access This article is distributed under the terms of the Creative Commons Attribution 4.0 International License (http:// creativecommons.org/licenses/by/4.0/), which permits unrestricted use, distribution, and reproduction in any medium, provided you give appropriate credit to the original author(s) and the source, provide a link to the Creative Commons license, and indicate if changes were made.

\section{References}

1. World Health Organization (2016) Global tuberculosis report 2015. World Health Organization, Geneva. Available via http://www. who.int/tb/publications/global_report/gtbr15 main text.pdf?ua=1. Accessed 5 Aug 2016

2. Fawibe AE et al (2011) Profile and outcome of unilateral tuberculous lung destruction in Ilorin, Nigeria. West Afr J Med 30(2):130 135

3. Palmer PE (1979) Pulmonary tuberculosis - usual and unusual radiographic presentations. Semin Roentgenol 14(3):204-243

4. Jeong YJ, Lee KS (2008) Pulmonary tuberculosis: up-to-date imaging and management. AJR Am J Roentgenol 191(3):834-844. doi:10.2214/AJR.07.3896

5. Ashour $\mathrm{M}$ et al (1990) Unilateral post-tuberculous lung destruction: the left bronchus syndrome. Thorax 45(3):210-212

6. Kao B et al (1989) The destroyed lung. Apropos of 46 surgical patients. Rev Pneumol Clin 45(6):237-242

7. Bobrowitz ID et al (1974) The destroyed tuberculous lung. Scand J Respir Dis 55(1):82-88

8. World Health Organization (2016) Global tuberculosis report 2015. Annex 4. Key TB indicators for individual countries and territories, WHO regions and the world. World Health Organization, Geneva. Available via http://www.who.int/tb/publications/global_report/ gtbr15 annex04.pdf?ua=1. Accessed 5 Aug 2016

9. Chakrabarti B, Calverley PM, Davies PD (2007) Tuberculosis and its incidence, special nature, and relationship with chronic obstructive pulmonary disease. Int J Chron Obstruct Pulmon Dis 2(3):263272

10. Birath G, Caro J, Malmberg R, Simonsson BG (1966) Airways obstruction in pulmonary tuberculosis. Scand J Respir Dis 47(1):27-36

11. Kim HY et al (2001) Thoracic sequelae and complications of tuberculosis. Radiographics 21(4):839-860. doi:10.1148/radiographics. 21.4.g01j106839
12. Kim Y et al (1997) Tuberculosis of the trachea and main bronchi. AJR Am J Roentgenol 168(4):1051-1056. doi:10.2214/ajr.168.4.9124114

13. Kim YT et al (2003) Long-term outcomes and risk factor analysis after pneumonectomy for active and sequela forms of pulmonary tuberculosis. Eur J Cardiothorac Surg 23(5):833-839. doi:10.1016/ S1010-7940(03)00031-9

14. Ashour M (1995) The anatomy of left bronchus syndrome. Clin Anat 8(4):256-261. doi:10.1002/ca.980080404

15. Porres DV et al (2013) Learning from the pulmonary veins. Radiographics 33(4):999-1022. doi:10.1148/rg.334125043

16. Eyler WR et al (1996) Rib enlargement in patients with chronic pleural disease. AJR Am J Roentgenol 167(4):921-926. doi:10. 2214/ajr.167.4.8819384

17. Takasugi JE, Godwin JD, Teefey SA (1991) The extrapleural fat in empyema: CT appearance. Br J Radiol 64(763):580-583. doi:10. 1259/0007-1285-64-763-580

18. Ko FW et al (2007) A 1-year prospective study of the infectious etiology in patients hospitalized with acute exacerbations of COPD. Chest 131(1):44-52. doi:10.1378/chest.06-1355

19. Sethi S (2010) Infection as comorbidity of COPD. Eur Respir J 35(6):1209-1215. doi:10.1183/09031936.00081409

20. Papi A et al (2016) Infections and airway inflammation in chronic obstructive pulmonary disease severe exacerbations. Am J Respir Crit Care Med 173(10):1114-1121. doi:10.1164/rccm.200506$8590 \mathrm{OC}$

21. Mata JM, Cáceres J (1996) The dysmorphic lung: imaging findings. Eur Radiol 6(4):403-414

22. Kosar A (2010) Pneumonectomy in children for destroyed lung: evaluation of 18 cases. Ann Thorac Surg 89(1):226-231. doi:10. 1016/j.athoracsur.2009.10.007

23. Pomerantz BJ et al (2001) Pulmonary resection for multi-drug resistant tuberculosis. J Thorac Cardiovasc Surg 121(3):448-453. doi:10.1067/mtc.2001.112339

24. Halezeroglu S et al (1997) Factors affecting postoperative morbidity and mortality in destroyed lung. Ann Thorac Surg 64(6):1635-8. doi:10.1016/S0003-4975(97)00999-5

25. Lee Y et al (2008) Surgical correction of postpneumonectomy-like syndrome in a patient with tuberculosis-destroyed lung. J Thorac Cardiovasc Surg 136(3):780-1. doi:10.1016/j.jtcvs.2007.12.035

26. Kam JC et al (2013) Postpneumonectomy-like syndrome presenting in a patient with treated pulmonary tuberculosis: a case report. J Med Case Rep 7:40. doi:10.1186/1752-1947-7-40 